\title{
Fixed-Point Number
}

National Cancer Institute

\section{Source}

National Cancer Institute. Fixed-Point Number. NCI Thesaurus. Code C89579.

A real number with a fixed number of dig its following the decimal or radix point. 